\title{
Usefulness of a rapid immunometric assay for intraoperative parathyroid hormone measurements
}

M.N. Ohe ${ }^{1}$, R.O. Santos ${ }^{3}$, I.S. Kunii ${ }^{1}$, A.B. Carvalho' ${ }^{2}$, M. Abrahão ${ }^{3}, \mathrm{O}$. Cervantes $^{3}$, M. Lazaretti-Castro ${ }^{1}$ and J.G.H. Vieira ${ }^{1}$
Disciplinas de ${ }^{1}$ Endocrinologia, ${ }^{2}$ Nefrologia, and

${ }^{3}$ Cirurgia de Cabeça e Pescoço, Escola Paulista de Medicina,

Universidade Federal de São Paulo, São Paulo, SP, Brasil
Correspondence

M.N. Ohe

Av. Cons. Rodrigues Alves, 804/51

04014-002 São Paulo, SP

Brasil

Fax: +55-11-5571-7547

E-mail: moniqueuyeno@aol.com

Research supported by FAPESP

(No. 00/00843-8)

Received August 29, 2002

Accepted April 24, 2003

\begin{abstract}
Intraoperative parathyroid hormone (IO-PTH) measurements have been proposed to improve operative success rates in primary, secondary and tertiary hyperparathyroidism (PHP, SHP and THP). Thirty-one patients requiring parathyroidectomy were evaluated retrospectively from June 2000 to January 2002. Sixteen had PHP, 7 SHP and 8 THP. Serum samples were taken at times 0 (before resection), 10, 20 and 30 min after resection of each abnormal parathyroid gland. Samples from 28 patients were frozen at $-70^{\circ} \mathrm{C}$ for subsequent tests, whereas samples from three patients were tested while surgery was being performed. IO-PTH was measured using the Elecsys immunochemiluminometric assay (Roche, Mannheim, Germany). The time necessary to perform the assay was $9 \mathrm{~min}$. All samples had a second measurement taken by a conventional immunofluorimetric method. We considered as cured patients who presented normocalcemia in PHP and THP, and normal levels of PTH in SHP one month after surgery and who remained in this condition throughout the follow-up of 1 to 20 months. When rapid PTH assay was compared with a routine immunofluorimetric assay, excellent correlation was observed $(\mathrm{r}=0.959, \mathrm{P}<0.0001)$. IO-PTH measurement showed a rapid average decline of $78.8 \%$ in PTH $10 \mathrm{~min}$ after adenoma resection in PHP and all patients were cured. SHP patients had an average IO-PTH decrease of $89 \% 30$ min after total parathyroidectomy and cure was observed in $85.7 \%$. THP showed an average IO-PTH decrease of $91.9 \%$, and cure was obtained in $87.5 \%$ of patients. IO-PTH can be a useful tool that might improve the rate of successful treatment of PHP, SHP and THP.
\end{abstract}

\section{Introduction}

Primary hyperparathyroidism (PHP) is a hypercalcemic disease due to an abnormal increase in parathyroid hormone (PTH) secretion by one or more parathyroid glands. The hallmark of this condition is the pres-
Key words

- Parathyroid hormone

- Intraoperative PTH

measurement

- Primary

hyperparathyroidism

- Secondary

hyperparathyroidism

- Tertiary

hyperparathyroidism 
thyroidectomy is the excision of the abnormal parathyroid gland(s) with preservation of the normal ones in order to achieve and maintain a postoperative normocalcemic state (3). Success rates for surgical treatment depend on the skill and experience of the surgeon in recognizing the pathologic changes and excising the correct amount of hyperfunctioning parathyroid tissue (4). Several methods have been proposed to aid the surgeon in deciding about the amount of parathyroid tissue to be resected. One of these approaches is intraoperative monitoring of PTH levels. Since the intact molecule of PTH containing residues 1 to 84 has a halflife of only 3 to 4 min (5-9), intraoperative assays are capable of quantitatively demonstrating the continued hypersecretion by remaining parathyroid tissue after excision of one or more enlarged glands (10).

Secondary hyperparathyroidism (SHP) is an acquired disorder most commonly seen in end-stage renal disease, since the uremic state presents a continuous stimulus to the parathyroid gland. About 5 to $10 \%$ of patients with chronic renal failure treated with long-term dialysis require surgery for SHP (11). The term tertiary hyperparathyroidism (THP) is used to describe the evolution of SHP to a state of apparent autonomous PTH secretion, resulting in elevated levels of serum calcium resembling PHP (12). In experienced hands, both subtotal parathyroidectomy and total parathyroidectomy with autotransplantation present good therapeutic results (13). Persistence/recurrence indicates an inadequate resection of hyperfunctioning tissue $(14,15)$. Reoperation is necessary for recurrent SHP in $15 \%$ of cases and presence of supernumerary glands, inadequate initial parathyroidectomy, and continued hyperplasia of remnant tissue are all potential contributors to this rate of failure (16).

The usefulness of a rapid intraoperative PTH measurement relates to the need to avoid postoperative persistent hypercalcemia in patients with PHP. Since failure to cure these patients is most often due to multiglandular disease not recognized by the surgeon or due to ectopic adenomas, measurement of intraoperative PTH can reduce the risk of failure by providing information about possible reminiscent tissue $(10,17)$. Another potential utility of intraoperative PTH is in minimally invasive surgeries and the need to achieve high cure rates with this procedure (18).

As in PHP, the intraoperative determination of intact PTH may be useful in surgery of patients with chronic renal failure and hyperparathyroidism, suggesting missed or hyperfunctioning supernumerary glands, when levels fail to decrease after parathyroid tissue removal (19). The aim of the present study was to observe retrospectively the decay profile of intact PTH in patients undergoing parathyroidectomy for PHP, refratory SHP or THP and to compare it to the cure observed in postoperative follow-up, in order to assess the utility of this procedure in predicting cure.

\section{Patients and Methods}

\section{Patients}

Thirty-one patients requiring parathyroidectomy were evaluated retrospectively during a period of 20 months (June 2000 to January 2002) at Escola Paulista de Medicina, Federal University of São Paulo, São Paulo, SP, Brazil. Sixteen had PHP, and fifteen had hyperparathyroidism related to chronic renal failure. Diagnosis of PHP was based on clinical features and confirmed by the findings of high total and/or ionized calcium levels, and high or inappropriate levels of intact PTH associated with normal renal function. Criteria for surgery in PHP were based on rules established by the National Institutes of Health (NIH, Bethesda, MD, USA) Consensus Conference of 1990 (20).

Among the patients with hyperparathyroidism secondary to chronic renal failure, 
7 had refractory SHP in dialysis treatment and 8 had THP (6 with renal transplantation and functioning grafts and 2 in dialysis treatment). Refractory SHP patients had severe SHP without hypercalcemia, and the term THP was used to describe the evolution of SHP to a state of apparent autonomous PTH secretion, resulting in elevated levels of serum calcium resembling PHP (12).

Specific indications for parathyroidectomy in hyperparathyroidism related to renal disease include a) persistent hypercalcemia, b) intractable pruritus not responding to intensive dialysis or to other medical interventions, c) progressive extraskeletal calcifications and/or persistent hyperphosphatemia despite the continued use of dietary phosphorus restriction and phosphate-binding agents, d) severe bone pain or fractures, and e) the development of calciphylaxis (21).

Patients were divided into three groups: the first included those with PHP, the second patients with refractory SHP and the third group patients with THP. Data analysis was carried out on these groups because of the particular characteristics and evolution of the patients. Characteristics of patients and preoperative laboratory findings are shown in Table 1. This study was approved by the University Ethics Committee (approval No.
$886 / 00$ ) and informed consent was obtained from all patients.

\section{Methods}

Baseline peripheral venous blood samples were obtained immediately after induction of anesthesia. After the parathyroid adenoma was removed, additional samples were collected at 10, 20 and 30 min after excision. When patient presented with multiglandular disease, blood samples were obtained 10, 20 and $30 \mathrm{~min}$ after each glandular excision. Samples from 28 patients were frozen at $-70^{\circ} \mathrm{C}$ for subsequent tests, whereas samples from 3 patients were tested while surgery was being performed.

PTH was measured by the Elecsys PTH Immunoassay (Elecsys 1010 System, Roche, Mannheim, Germany). The test is an immunometric assay based on monoclonal antibodies, magnetic particles as the solid phase and ruthenium complex as the chemiluminescent label. The time needed to perform the assay was $9 \mathrm{~min}$. Analytical sensitivity (lower detection limit) was $1.20 \mathrm{pg} / \mathrm{ml}$. To validate the rapid PTH assay, 170 samples were also submitted to a standard immunofluorimetric assay (22). During the postoperative follow-up (1 to 20 months after sur-

\begin{tabular}{lccc}
\multicolumn{4}{l}{ Table 1. Characteristics of patients and preoperative laboratory findings. } \\
\hline & Primary HP & Secondary HP & Tertiary HP \\
\hline $\begin{array}{lcc}\text { No. of patients } \\
\text { Sex (female:male) }\end{array}$ & 16 & 7 & 8 \\
Mean age (years) & $52(12-80)$ & $31.7(22-58)$ & 40 (23-54) \\
$\begin{array}{l}\text { Mean preoperative iPTH } \\
\text { (RV: } 10-70 \text { pg/ml) }\end{array}$ & $248.6(86-1019)$ & $1312.5(248-2500)$ & $503.2(140-1774)$ \\
$\begin{array}{l}\text { Mean preoperative ionized } \\
\text { calcium (RV: } 1.12-1.32 \mathrm{mmol} / \text { ) }\end{array}$ & $1.45(1.32-1.89)$ & $1.20(1.13-1.27)$ & 1.56 (1.37-2.06) \\
Years on dialysis & & $6(3-14)$ & $7.8(4-14)$ \\
Years of renal graft $(\mathrm{N}=6)$ & & 1.5 (0.16-4) \\
\hline
\end{tabular}

HP, hyperparathyroidism; iPTH, intact parathyroid hormone; RV, reference value. Range is shown in parentheses. 
gery), we considered as cured patients who presented normocalcemia in the case of PHP and THP, and normal PTH levels in SHP.

Serum total calcium, phosphorus, total alkaline phosphatase and urinary calcium were measured by standard automatic assays. Serum ionized calcium was measured using an ion-specific electrode (AVL 9180 Electrolyte Analyzer, Roswell, GA, USA), with a reference value of 1.12 to $1.32 \mathrm{mmol} / \mathrm{l}$.

\section{Statistical analysis}

Data were analyzed by the paired $t$-test and Spearman correlation test. A P value of $<0.05$ was considered to be significant.

\section{Results}

The correlation between the rapid PTH assay and the standard immunofluorimetric assay was $r=0.959(\mathrm{P}<0.0001)$ (Figure 1$)$.

Among the 16 patients with PHP, 14 had uniglandular disease and 2 multiglandular disease. In the 14 patients with PHP and uniglandular disease there was an average decrease of $78.8 \%$ in intact PTH concentrations 10 min after abnormal parathyroid resection. Intact PTH levels continued to fall 20 and 30 min after abnormal parathyroid removal by about 83.7 and $87.1 \%$ from the baseline values, respectively. There was a significant difference in PTH values between

Figure 1. Correlation between the results of rapid intraoperative intact parathyroid hormone (PTH) determined by the Elecsys immunochemiluminometric assay and by a standard immunofluorimetric assay (IFMA). $\mathrm{N}=$ number of patients; $r$ = correlation coefficient.

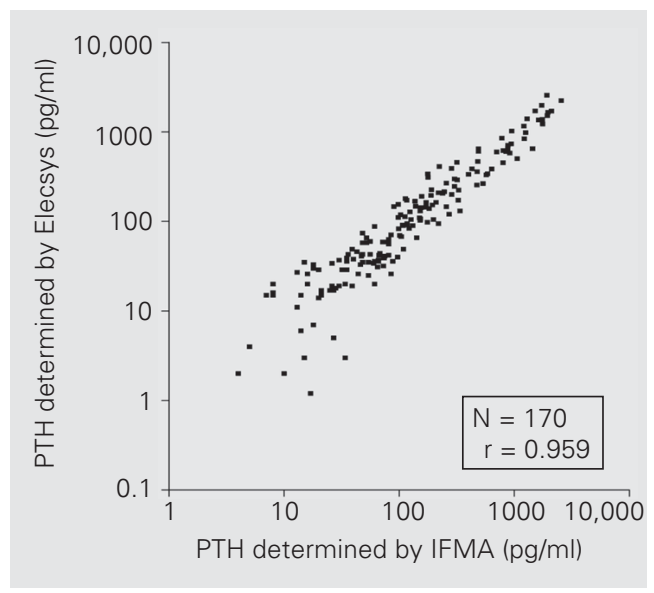

times 10 and $20 \min (\mathrm{P}=0.0170)$ and between times 20 and $30 \min (\mathrm{P}=0.0027)$ after resection.

It is interesting to note that in PHP with multiglandular disease $(\mathrm{N}=2)$, as expected, the decay profile was different from that for uniglandular disease, with a stepwise decrease in intraoperative PTH concentrations following each gland removal. The percent changes in PTH from baseline for the 14 patients with PHP with uniglandular disease are presented in Figure 2A and the decay profile for PHP patients with multiglandular disease is presented in Figure 2B.

All patients with PHP were considered cured during the postoperative follow-up, with a mean $78.8 \%$ reduction in PTH levels, suggesting that the assay could predict cure in this group of patients.

As expected when multiglandular disease is involved, measurements of intraoperative rapid intact $\mathrm{PTH}$ in refractory SHP patients followed a sequential decrease pattern after each gland removal. Patients with refractory SHP showed a mean intact PTH decrease of $89 \% 30 \mathrm{~min}$ after total parathyroidectomy, indicating high cure rates. In this group, cure was observed in $85.7 \%(6 / 7)$ of patients. In 5 of these 7 refractory SHP patients, intact PTH absolute values in the final intraoperative samples were still high (mean $128.5 \mathrm{pg} / \mathrm{ml}$, range: $83-311 \mathrm{pg} / \mathrm{ml}$ ), but during the postoperative follow-up $85.7 \%$ of SHP patients were considered cured. The PTH decrease observed in THP patients resembled that observed in PHP, with a faster PTH reduction than observed in SHP (Figure 2C). Patients with THP had a mean rapid intact PTH decay of $91.9 \%$ from baseline 30 min after removal of all recognized parathyroid tissue, with a cure rate of $87.5 \%(7 / 8)$.

\section{Discussion}

Failure to surgically cure hyperparathyroidism is usually related to multiglandular disease, ectopic adenomas, misinterpretation 
of frozen-section pathologic findings, and incorrect diagnosis of PHP $(23,24)$. Attempting to decrease failure rates, experienced surgeons have reported large series with excellent results using different surgical approaches to parathyroidectomy (25). Surgical treatment of PHP has undergone some changes in recent years. The standard technique of bilateral neck exploration with identification of parathyroid adenoma together with the three other normal glands is being replaced in selected cases at many medical centers with a less time-consuming procedure of unilateral neck exploration based on preoperative localization by ${ }^{99 \mathrm{~m}} \mathrm{TC}$-sestamibi scans (26). The utility of a test that can assure the surgeon that multiglandular disease is not present after the excision of a large parathyroid gland, or that can help localize intraoperatively an eluding adenoma, and quantitatively confirm the adequate excision, is clear.

Secretion of PTH is suppressed in the remaining normal parathyroid glands after removal of all hyperfunctioning tissue (9) and this, coupled with the rapid clearance of intact PTH, allows the measurement of intraoperative PTH to determine its disappearance rates. The clinical utility of rapid intraoperative PTH measurements in parathyroidectomy was first reported in 1988 using a modified intact PTH immunoradiometric assay (27). The authors observed that PTH concentrations declined to a mean of $40 \%$ of baseline values 15 min after successful parathyroid adenomectomy in 12 patients, and they suggested that the surgical judgment and skill of the surgeon to determine surgical cure could be complemented with the intraoperative PTH assay.

Thereafter, rapid assays were developed using radioactive $(4,28,29)$ as well as nonradioactive formats $(10,30)$. Irvin III and Deriso (10) documented an immunochemiluminometric assay for intact PTH (Nichols Institute Diagnostics, San Juan Capistrano, CA, USA) for use as a rapid intraoperative PTH assay in surgery for PHP, and reported a sensitivity of $97 \%$, specificity of $100 \%$, and an overall accuracy of $97 \%$ (31). Gordon and co-workers (32) suggested that a $50 \%$ decrease in the 10-min post-excision sample accurately predicts the disease state in $89 \%$ of patients with PHP. Findings of $88 \%$ accuracy in predicting cure using the criterion of
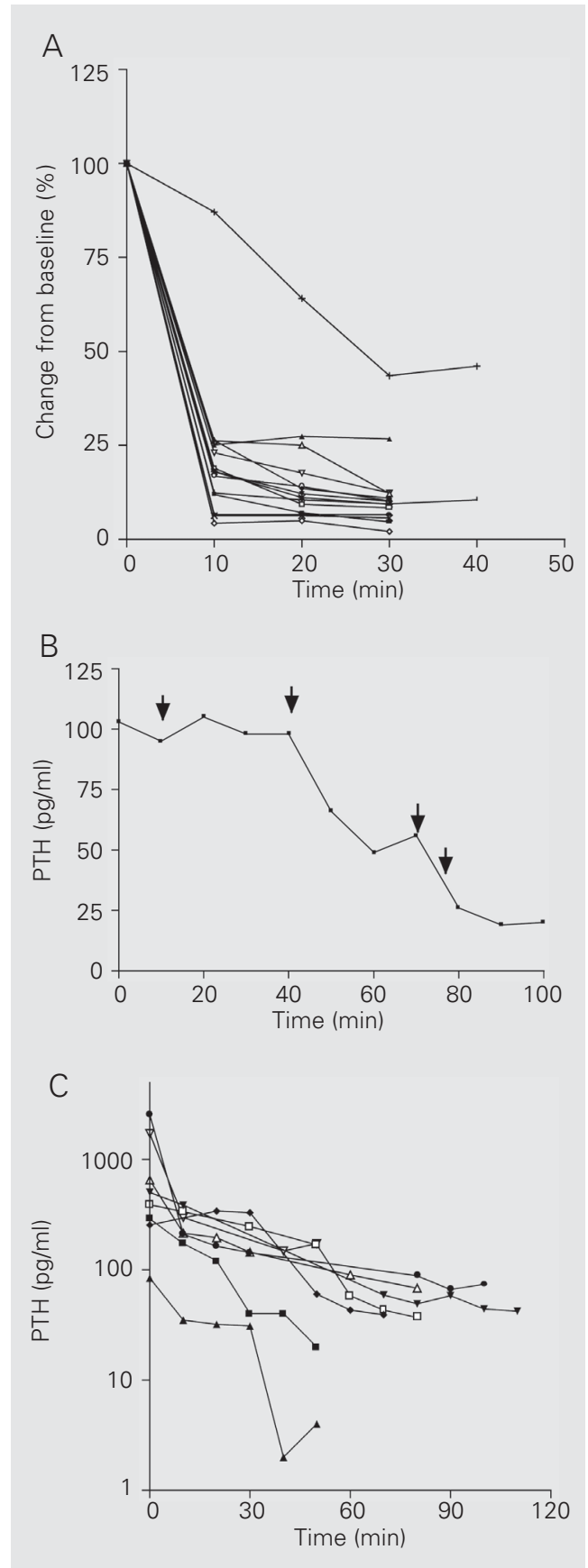

Figure 2. Intraoperative circulating concentrations of intact parathyroid hormone (PTH) during parathyroid gland resection. Intact PTH was determined by the 9-min Elecsys assay system. A, Reduction of intact PTH in 14 primary hyperparathyroid patients with a single adenoma. Data are reported as percent. $B$, Reduction of intact PTH $(\mathrm{pg} / \mathrm{ml})$ in primary hyperparathyroid patients with multiglandular disease. Arrows indicate parathyroid gland resection. $C$, Intact PTH concentration $(\mathrm{pg} / \mathrm{ml})$ of 8 tertiary hyperparathyroid patients. 
a 50\% decrease at 5-10 min have been reported, and of $97 \%$ if patients with delayed decreases of intraoperative PTH are included (33).

The assay used in the present study showed a good correlation with a standard PTH immunofluorimetric assay used in our routine $(\mathrm{r}=0.959, \mathrm{P}<0.0001)$ and documented the rapid decline in PTH levels after excision of significant amounts of parathyroid tissue, as previously described by other authors $(4,10,27,29,30,33)$ with similar assays.

All patients with PHP were considered to be cured after parathyroidectomy and this correlated with an average $78.8 \%$ reduction of PTH values from baseline at $10 \mathrm{~min}$ after adenoma removal, confirming the ability of the assay to predict cure. Patients with SHP showed an average decrease of $89 \% 30 \mathrm{~min}$ after parathyroidectomy with the assay showing the ability to predict cure in $85.7 \%$ of patients. Even if final intraoperative PTH levels were still high in SHP patients, the postoperative follow-up showed normal PTH levels in $85.7 \%$. This pattern of delayed PTH clearance has been described in SHP patients receiving dialysis compared to patients with normal renal function (19). The decreased renal function might explain the final abnormal intraoperative PTH levels in patients that eventually were considered to be cured. In these cases it may be of interest to consider the percent decay in intraoperative PTH values, instead of absolute values after total parathyroidectomy. Among patients with THP, the rapid PTH decay profile showed a pattern resembling PHP, probably due to the presence of a functioning renal graft in these patients $(\mathrm{N}=6)$. In THP patients, intraoperative PTH was able to predict cure in $87.5 \%$ of cases, with a mean 91.9\% decrease in PTH values from baseline to 30 min after parathyroidectomy. In conclusion, the rapid PTH assay used in this study might be useful to improve success rates in parathyroidectomy surgeries in primary, secondary and tertiary hyperparathyroidism.

\section{References}

1. Melton III LJ (1991). Epidemiology of primary hyperparathyroidism. Journal of Bone and Mineral Research, 6 (Suppl 2): S25-S30.

2. Silverberg SJ, Bilezikian JP, Bone HG, Talpos GB, Horwitz MJ \& Stewart AF (1999). Therapeutic controversies in primary hyperparathyroidism. Journal of Clinical Endocrinology and Metabolism, 84: 2275-2282.

3. Carneiro D \& Irvin III GL (2000). Late parathyroid function after successful parathyroidectomy guided by intraoperative hormone assay (QPTH) compared with standard bilateral neck exploration. Surgery, 128: 925-929.

4. Irvin III GL, Dembrow VD \& Prudhomme DL (1991). Operative monitoring of parathyroid gland hyperfunction. American Journal of Surgery, 162: 299-302.

5. Davies C, Demeure MJ, St John A \& Edis AJ (1990). Study of intact (1-84) parathyroid hormone secretion in patients with hyperparathyroidism. World Journal of Surgery, 14: 355-360.

6. Fischer S, Flentje D, Kettelhack C, Schmidt-Gayk J, Buhr H \& Herfarth C (1990). Intraoperative and postoperative PTH secretion mode in patients with hyperparathyroidism. World Journal of Surgery, 14: 349-354.

7. Flentje D, Schmidt-Gayk H, Fischer S, Stern J, Blind E, Buhr H \& Herfarth C (1990). Intact parathyroid hormone in primary hyperparathyroidism. British Journal of Surgery, 77: 168-172.

8. Blind E, Schmidt-Gayk H, Scharla S, Flentje D, Fischer S, Göhring U \& Hitlzler W (1988). Two-site assay of intact parathyroid hormone in the investigation of primary hyperparathyroidism and other disorders of calcium metabolism compared with a midregion assay. Journal of Clinical Endocrinology and Metabolism, 67: 353-360.

9. Brasier AR, Wang CA \& Nussbaum SR (1988). Recovery of parathyroid hormone secretion after parathyroid adenomectomy. Journal of Clinical Endocrinology and Metabolism, 66: 495-500.

10. Irvin III GL \& Deriso GT (1994). A new, practical intraoperative parathyroid hormone assay. American Journal of Surgery, 168: 466468.

11. Packman KS \& Demeure MJ (1995). Indications of parathyroidectomy and extent of treatment for patients with secondary hyperparathyroidism. Surgical Clinics of North America, 75: 465-482.

12. Indridason OS \& Quarles D (1999). Tertiary hyperparathyroidism and refractory secondary hyperparathyroidism. In: Favus MJ (Editor), Primer on the Metabolic Bone Diseases and Disorders of Mineral Metabolism. 4th edn. Lippincott Williams \& Wilkins, Chicago, IL, USA.

13. Rothmund M, Wagner PK \& Schark C (1991). Subtotal parathyroidectomy versus total parathyroidectomy and autotransplantation in secondary hyperparathyroidism: a randomized trial. World Journal of Surgery, 15: 745-750.

14. Henry JFR, Denizot A, Audiffret J \& France G (1990). Results of reoperations for persistent or recurrent secondary hyperparathyroidism in hemodialysis patients. World Journal of Surgery, 14: 303-307.

15. Donckier V, Decoster-Gervy C \& Kinnaert P (1997). Long-term re- 
sults after surgical treatment of renal hyperparathyroidism when fewer than four glands are identified at operation. Journal of the American College of Surgeons, 184: 70-74.

16. Clary BM, Garner SC \& Leight Jr GS (1997). Intraoperative parathyroid hormone monitoring during parathyroidectomy for secondary hyperparathyroidism. Surgery, 122: 1034-1039.

17. Mandell DL, Genden EM, Mechanick JI, Bergman DA, Diamond EJ \& Urken ML (2001). The influence of intraoperative parathyroid hormone monitoring on the surgical management of hyperparathyroidism. Archives of Otolaryngology - Head and Neck Surgery, 127: 821-827.

18. Chen H, Sokoll L \& Udelsman R (1999). Outpatient minimally invasive parathyroidectomy: a combination of sestamibi-SPECT Iocalization, cervical block anesthesia, and intraoperative parathyroid hormone assay. Surgery, 126: 1016-1022.

19. Lokey J, Pattou F, Mondragon-Sanchez A et al. (2000). Intraoperative decay profile of intact (1-84) parathyroid hormone in surgery for renal hyperparathyroidism - a consecutive series of 80 patients. Surgery, 128: 1029-1034.

20. NIH (1991). Conference: diagnosis and management of asymptomatic primary hyperparathyroidism: consensus development conference statement. Annals of Internal Medicine, 114: 593-597.

21. Llach $F$ (1990). Parathyroidectomy in chronic renal failure: indications, surgical approach, and the use of calcitriol. Kidney International Supplement, 29: S62-S68 (Review).

22. Vieira JGH, Nishida SK, Kasamatsu TS, Amarante EC \& Kunii IS (1994). Development and clinical application of an immunofluorimetric assay for intact parathyroid hormone. Brazilian Journal of Medical and Biological Research, 27: 2379-2382.

23. Levin KE \& Clark OH (1989). The reasons for failure in parathyroid operations. Archives of Surgery, 124: 911-915.

24. Jarhult J, Nordenstrom J \& Perbeck L (1993). Reoperation for suspected primary hyperparathyroidism. British Journal of Surgery, 80: 453-456.
25. Boggs JE, Irvin III GL, Carneiro D \& Molinari AS (1999). The evolution of parathyroidectomy failures. Surgery, 126: 998-1003.

26. Garner SC \& Leight Jr GS (1999). Initial experience with intraoperative PTH determinations in the surgical management of 130 consecutive cases of primary hyperparathyroidism. Surgery, 126: 11321138.

27. Nussbaum SR, Thompson AR, Hutcheson KA, Gaz RD \& Wang CA (1988). Intraoperative measurement of parathyroid hormone in the surgical management of hyperparathyroidism. Surgery, 104: 11211127.

28. Proye CAG, Goropoulos A, Franz C, Carnaille B, Vix M, Quievreux JL, Couplet-Leblon G \& Racadot A (1991). Usefulness and limits of quick intraoperative measurements of intact (1-84) parathyroid hormone in the surgical management of hyperparathyroidism: sequential measurements in patients with multiglandular disease. Surgery, 110: 1035-1042.

29. Ryan MF, Jones SR \& Barnes AD (1990). Modification to a commercial immunofluorimetric assay permitting intraoperative monitoring of parathyroid hormone levels. Annals of Clinical Biochemistry, 27: 65-68.

30. Kao PC, van Heerden JA \& Taylor RL (1994). Intraoperative monitoring of parathyroid procedures by a 15-min parathyroid hormone immunochemiluminometric assay. Mayo Clinic Proceedings, 69: 532-537.

31. Boggs JE, Irvin III GL, Molinari AS \& Deriso GT (1996). Intraoperative parathyroid hormone monitoring as an adjunct to parathyroidectomy. Surgery, 120: 954-958.

32. Gordon LL, Snyder III WH, Wians Jr F, Nwariaku F \& Kim LT (1999). The validity of quick intraoperative parathyroid hormone assay: an evaluation in seventy-two patients based on gross morphologic criteria. Surgery, 126: 1030-1035.

33. Sokoll LJ, Drew H \& Udelsman R (2000). Intraoperative parathyroid hormone analysis: a study of 200 consecutive cases. Clinical Chemistry, 10: 1662-1668. 